\title{
Success Factors on Which to Invest in Mega Sport Events: Lessons from the Past and Insights into the Future
}

\author{
Giuseppe Vito, Alessandra Sorrentini, Davide Di Palma*, Vincenzo Raiola, Maria Tabouras
}

Department of Movement and Wellness Sciences, University of Naples Parthenope, Naples, Italy

Email address:

davide.dipalma@uniparthenope.it (D. Di Palma)

${ }^{*}$ Corresponding author

To cite this article:

Giuseppe Vito, Alessandra Sorrentini, Davide Di Palma, Vincenzo Raiola, Maria Tabouras. Success Factors on Which to Invest in Mega Sport Events: Lessons from the Past and Insights into the Future. International Journal of Economics, Finance and Management Sciences. Vol. 4, No. 4, 2016, pp. 190-198. doi: 10.11648/j.ijefm.20160404.14

Received: June 20, 2016; Accepted: June 28, 2016; Published: July 21, 2016

\begin{abstract}
The aim of this paper is to define the broad conditions in the predisposition of the bid to host a mega sport event that allow: a) the success in the selection; b) the maximization of benefits in the pre, during and post-event phases; c) the environmental and social sustainability of touristic flows attracted by the event. The specific reference is to the Italian bid to host the 2024 Olympic Games in Rome, to which literature has not yet dedicated specific contributions. The methodology consists in a multiple case study regarding six mega events (four successful and two unsuccessful ones) specifically focused on the outcome of the bid and on the level of benefits achieved by local communities having hosted such events. The time horizon of the study concerns the short term in particular, but it also examines the implications in the medium / long term. The results consist in the identification of the best practices used in the cases under consideration -with particular reference to the ability of primary stakeholders to build effective relationships each other and with other stakeholders- and in their transposition, after the necessary adaptation to the political, social and infrastructural pre-existing conditions, to the suction of Rome to host the 2024 Olympic Games. Findings can be transferred to the various stakeholders of the event under design with the aim to provide a contribution of the scientific community to the best setting of the initiative with particular reference to the preparation of the bid.
\end{abstract}

Keywords: Olympic Games, Bidding Process, Sport Management, Government Support, Infrastructural Conditions

\section{Introduction}

Mega events, thanks to their size and relief, produce extraordinarily high standards on tourism, media coverage, prestige and economic impact on the hosting community's structure and organization. Therefore, they are events of enormous status and prestige, attractive to hosting communities, mainly for their ability to increase the attractiveness and the incoming touristic flows of a destination not only in the short but also in the medium-long term. Most representative example of such events are world scale sporting events, assigned, through a bidding process, to the most valuable offer. These events include the Summer and Winter Olympic Games and the Football World Cup. Accordingly, what determined in the past decades the growing interest in hosting a mega sport event is its ability to generate flows of tourists, attract the attention of the media and most importantly, the substantial economic impact that is able to produce on the hosting community on different territorial levels (city, regional and national). In fact, the choice of the hosting location is a result of a complex and articulated process, which involves national and local political agents as well as national and international sports government bodies. Taking into account the residents' opinions and the economic potential of the location, these parties agree on rather or not to host an event, while the promoters of the sport select the location that will host it. The selection procedures (bid) are to be regarded, as political and economic competitions between individuals who are applying to organize the same sports event. The participants in the bidding procedures require the ability to bring together subjects and organizations with different expectations, interests and skills (sporting federations, local authorities, economic partners, media, etc.) but sharing 
the goal to win the bid to host the event. The proposal must therefore be structured in such a way as to satisfy, as far as possible, all the different expectations and must also be founded, in order to be competitive, on some general principles regarding the culture relative to a specific sport in the proposer territorial context. The locations interested in hosting the event must implement suitable strategies and appropriate monitoring procedures in order to run for the right event at the right time, in view of optimizing the attended bidding procedures by selecting those, which are most promising as regards the possibility of success.

The focus of the research is to detect the conditions of the bidding process to host a mega sport event that can lead to success in being selected in prospective to a positive cost/benefit relation in short and long term. In other words, we aim to find the key success factors in presenting the bid. To do so in the following we will refer to the Summer Olympics, but the method and the findings can be extended to other types of mega events (Winter Olympics, Soccer World Cup and other major events).

In addition, this paper uses the outcome of the analysis to identify the key factors on which the Rome 2024 candidacy should invest on and, at the same time, to detect the criticalities to monitor in order to have a good chance of winning the bid.

In the following pages will be firstly shown the literature review of the research's topic, to then proceed with the description of the method used and the procedure followed for the case selection and to close, are described the cases analysis and discussion of the results.

\section{Literature Review}

In recent decades a wide international literature has recognized in mega sport events, including the Olympics, and in the bid procedures, an important topic of research and study. Several authors have turned their attention in the analysis and measurement of the effects that these types of events, alike the design and organization of an official candidacy itself, are capable of producing in terms of development and economic, territorial and social revaluation (Brown et al., 2012; Glynn, 2008; Hiller, 2000; Kasimati, 2003). In this field, Waitt (2003) e White (2011) study the social phenomenon of the growing enthusiasm among the Australian population in relation to the Sydney Olympics 2000, able to stimulate the economic aspect of the propensity to consumption. Furthermore, studies conducted from Rose and Spiegel (2011) and Tufts (2004) justify the substantial economic burden to incurred for the organization of the Olympics in the face of the consequent increase in exports and employment. In this line of research are inserted both the contributions of O'Brien (2006) that theorize a business leveraging of mega sports events to be exploited for the economic realities of the country where a mega event is organized, and Lee and Taylor (2005) that demonstrate how through the flow of tourists directly and indirectly connected to a mega event, specifically the 2002 FIFA World Cup in
South Korea, generated considerable economic benefits in all the productive sectors. On the other hand, there are some Authors that rather than pursue the approach of the aforementioned literature tend to analyse the adverse effects and the different criticalities that impact on the economies of the candidate that are not successful in the bid procedure, with the consequent non-remuneration of the invested resources (Bandyopadhyay, 2013; Hiller, 2000; Swart and Bob, 2004; van Dijk and Weitkamp, 2013).

Likewise, the literature that has addressed these topics has deepened the study of the key factors that can affect the success or otherwise of a candidacy in the procedure of bid to host a mega event as the Olympics. In the following, is carried out a brief literature review regarding the topics of greatest interest for the present contributions: identify the key factors of success of the biding process for the mega sport events with specific reference to the holistic, technical and managerial perspectives. The Authors who have tackled the issue through these points of view have found a number of specific factors in past mega events, mainly the Olympics, capable of leading to successful bids.

More specifically, according to the holistic point of view (Booth and Tatz 1994; Hitch and Mihalik, 2002; Little, 1997; Westerbeek, Turner, \& Ingerson, 2002; Shoval, 2002), emerge as key factors:

- political support

- responsibility

- bid team composition

- relationship marketing

- ability to organize an event

- communication and exposure

- infrastructure factor

Contrariwise, a technical point of view which explores the infrastructure factor is referred to the presence or lack of venues and their eventual conditions in terms of structure and geographical distance from where the event takes place (Alberts 2009; Haugen, 2005; Liao and Pitts, 2006 Newman, 2007; Swart \& Bob, 2004). More specifically:

- Existing Venues: The proportions of completed venues requiring no further modification

- Venues Construction: venues requiring substantial reconstruction work or still under construction

- Planned Venues: planned venues that would only be built on approval of the bid

- The number of available hotel beds within 50 minutes of travelling time

Last but not least, we have a managerial point of view in partially related to the holistic view described before, but analyzed from a different prospective. For instance, Gratton and Preuss (2008) study the importance of the "political support" factor, in terms of financial coverage that the same can guarantee for the event organization. Furthermore, several factors (relationship marketing, ability to organize an event, communication and exposure, infrastructure factor) are contextualized in the importance of having a coordinated and efficient management between the different primary and secondary stakeholders that contribute directly and indirectly to the event (Hautbois et al., 
2012; Xiaoyan et al., 2008; Zhao, 2002).

The selected cases were analysed using a SWOT analysis approach. In literature, many scholars agree that conducting a SWOT analysis is useful for host cities because it helps event organizers and tourism providers to identify how the strengths of their city can be matched with the existing opportunities in the operating environment (Shank, 2009). The analysis of weaknesses in relation to their Event leveraging of mega sport events operating environment (resident support, economic stability and political support) can also provide useful insights for event organizers and tourism providers to carefully plan how the host city can leverage the benefits from the sport event (O'Brien and Chalip, 2007).

\section{Method}

The method consists in a multiple case study (Baxter \& Jack, 2008; Eisenhardt, 1989) of six mega events (four successful and two unsuccessful ones) specifically aimed to define the key factors of success or failure of a bid.

Case study research represents a tool that explores in depth real situations often providing insights that instruments that tend to translate the concepts into measures cannot provide. The multiple case study method appeared particularly appropriate for the object studied. The Authors as a first step conducted a content analysis of the of official IOC (International Olympic Committee) reports regarding the 2008-2020 time range, using the ATLAS.ti software. The outcome of the analysis permitted us to proceed to the second step, where we analysed the selected cases in a structured and rational way using the SWOT analysis.

\section{Cases Selection}

- Data Collection

We collected all of the 17 bids to host Summer Olympic Games presented by 12 cities from 2008 to 2020 as some of the cities examined, presented a bid to host the event more than once.

- Sampling

From the group of different non-probability (Purposive) sampling techniques we have chosen Maximum Variation Sampling with the aim to explore common themes related to success or failure of the bid and/or the sustainability of tourism.

Using a maximum variation sampling method allows researcher to select a small number of units or cases that maximize the diversity relevant to the research question.
Outlier cases (that is, those that are extreme, deviant or atypical) can in fact reveal more information than the potentially representative case.

- Inclusion Criteria

In order to capture the largest possible number of perspectives on the theme of the research, the Authors used, as inclusion criteria:

- Final result of the Olympic Bid participations

- Continental location

- Results obtained in the first vote

More specifically, for what concerns the final results the outcome of the candidates in the reporting period, were either successful or unsuccessful in all of their attempts; the continental location of the cities that have submitted the bid in the considered period is different for each of the 6 cities considered apart from the two Asian cases; as for the third and last inclusion criteria, have been exclusively considered the nominations that obtained a minimum of 17 votes during the first voting rounds.

- Selected Cases

The application of the above inclusion criteria led to the identification of 6 cases study:

- Beijing 2008 (Asia)

- Istanbul 2008 (Europe - Asia)

- London 2012 (Europe)

- Rio de Janeiro 2016 (South America)

- Chicago 2016 (North America)

- Tokyo 2020 (Asia)

Among these, candidates, Istanbul 2008 and Chicago 2016, have achieved a negative result, meaning that they were not selected to host the Games, while Beijing 2008, London 2012, Rio 2016, Tokyo 2020 were winners of the procedure of bid.

\section{Cases Analysis}

We conducted a Content Analysis (Berelson, 1952) of:

- the Reports of the IOC Evaluation Commission 2008 2020

- Bids presented (17 documents)

In this regard, we uploaded a total of 500 pages of documents, into ATLAS.ti, a qualitative data analysis software. The results of the Content Analysis, allowed to structure a SWOT analysis for each one of the selected cases under study. First, there are represented the SWOT analysis regarding the Istanbul and Beijing candidacies, both presented for the 2008 Olympic bid.

Tab. 1. SWOT Analysis - Beijing 2008.

\begin{tabular}{ll}
\hline Strengths & Weaknesses \\
\hline - Strong Government support & - Need to improve the transportation system \\
- Guarantee to cover potential economic shortfalls of OCOG & - Need to improve the dining and mail facilities \\
- Consistency with policies of urban and social development & \\
- High support of public opinion $(96 \%$ both in Beijing and other urban areas.) & Threats \\
$\begin{array}{l}\text { Opportunities } \\
\text { - Population and economic growth }\end{array}$ & $\begin{array}{l}\text { - Limited experience in international sport broadcasting } \\
\text { - Affordable and significant legacy for Chinese sport. }\end{array}$ \\
\hline
\end{tabular}

Source: Our elaboration 
Tab. 2. SWOT Analysis - Istanbul 2008.

\begin{tabular}{ll}
\hline Strengths & Weaknesses \\
\hline - Strong Government support & - Uncertainties regarding the overall status and projections of Games finance \\
- Historic and cultural icon & - Need to improve the public transportation system \\
- Significant support of public opinion $(86 \%$ both in Istanbul & - Difficult access to a number of venues \\
and other urban areas.) & Threats \\
Opportunities & - Instability of the economic, monetary and political system \\
- Significant legacy for Turkish sport. & - Uncertainty regarding the transport infrastructure budget and timelines \\
\hline
\end{tabular}

Source: Our elaboration

More in detail, among the main strengths of the Beijing candidacy that determined its success, we find the aspect of the strong support from national and local levels of government. In fact, the Chinese Central and Beijing Municipal governments provided a financial guarantee. This, guaranteed the funding (for an amount over US\$ 16 billion) of any shortfall, the construction of infrastructure and venues and working capital for the OCOG (Organizing Committee for the Olympic Games). Despite also boasting a high level of government support $(88 \%$ in Turkey and $89 \%$ in Istanbul), the bid showed obvious weaknesses inherent to the ability to ensure financial coverage of expenses related to activities not only directly related to the Olympic Games, but also to external management. In addition, to further penalize such candidacy has been the socio-economic instability of the whole country and the lack of public infrastructure (especially in the public transportation sector) making Istanbul inadequate to support an event of such sport, economic, political and social relevance. On the other hand, the growth and the economic development that China has experienced in the past decades became an opportunity for the Olympic Committee to exploit; still, the cultural traditions and the strong sense of belonging of the Asian population were identified as stimulating factors for the effective success of the event, able to limit the impact of the critical points that emerged in relation to the huge traffic flows and to the inexperience in hosting mega sporting events.

In relation to the 2012 Olympic Bid, was analyzed the London candidature alone, which as previously specified, represents a case of success.

Tab. 3. SWOT Analysis - London 2012.

\begin{tabular}{ll}
\hline Strengths & Weaknesses \\
\hline $\begin{array}{l}\text { - Strong Government support } \\
\text { - Guarantee to cover potential economic shortfalls of OCOG }\end{array}$ & - Low public opinion support (68\% in London, 70\% through the Country) \\
$\begin{array}{l}\text { - Location of the Olympic Park } \\
\text { Transportation system }\end{array}$ & Threats \\
Opportunities & - Need of careful management to ensure that all planned facilities are completed on time \\
\hline - Regeneration and development of the Lower Lea Valley &
\end{tabular}

Source: Our elaboration

Conform to the cases studied above, the candidacy counted on the strong Queen's, national government and the GLA (Greater London Authority) support built, regardless the political orientation, on the solid ability to cope with any potential economic shortfalls of OCOG; in fact, the UK government has guaranteed it would act as the ultimate financial guarantor to cover any shortfall from the Games.

In addition, the budgeting process (for a total of more than US $\$ 20$ billion) appeared very detailed and meticulous with a series of well-supported and documented accounting and financial assumptions able to highlight a very high practical embodiment. Furthermore, London avails an excellent transportation network and the Olympic village location was very convenient as the $49 \%$ of the athletes would have to attend their sporting competitions in the immediate distance.
The Olympics would have been the determining factor for the regeneration and economic development of Lower Lea Valley area, site for the Olympic Park, and various other suburban areas. This would obviously imply the possible threat that the planned investments in territorial upgrade and urban areas would not be finished in time but the arrogation of 3.8 billion USD guaranteed to fund Olympic infrastructure, greatly limited this criticality. The only actual weakness of the London candidacy was the lack of public opinion support compared to the other cases studied, which however could not in any way affect the considerable strengths listed above, in confirmation of the overall positivity as assessed.

As for the 2016 edition we conducted a SWOT Analysis on the two finalists of the biding process Rio, who was the edition's winner and Chicago. 
Tab. 4. SWOT Analysis - Rio 2016.

\begin{tabular}{ll}
\hline Strengths & Weaknesses \\
\hline - Strong Government support & - Need to improve the transportation system \\
- Guarantee to cover potential economic shortfalls of OCOG & - Need to improve the accommodation system \\
- Consistency with policies of urban and social development & - Medium support of public opinion (85\% Rio, 69\% through the country) \\
- Sport experience (Pan-American Games 2007, FIFA World Cup 2012) & \\
Opportunities & $\begin{array}{l}\text { Threats } \\
\text { - Social integration }\end{array}$ \\
- Affordable and significant legacy & - Need of careful management of the urban regeneration program \\
\hline
\end{tabular}

Source: Our elaboration

Tab. 5. SWOT Analysis - Chicago 2016.

\begin{tabular}{ll}
\hline Strengths & Weaknesses \\
\hline - Location of the Olympic Park & - Medium Government support \\
- Transportation system & - Project complexity both from financial and infrastructural point of view \\
- Consistency with policies of urban development & Low public opinion support (67\% support in Chicago and $61 \%$ through the Country) \\
$\begin{array}{l}\text { Opportunities } \\
\text { - Organizing the Games without the need for public } \\
\text { investment in major permanent venues }\end{array}$ & Threats \\
\hline
\end{tabular}

Source: Our elaboration

It emerges a significant difference on the level of government support and financial sustainability in the two cases examined. The Rio candidacy had the full support of the three levels of government (federal, state and city) across all political parties and private sector, as well as the strong cooperation and involvement of the National Olympic Committee and the athletes. Actually, Rio 2016 bid plan forms part of the Brazilian Government's vision to invest in sport as a catalyst for social integration through four main programs: social inclusion through sport and leisure; elite sport; expansion of sports infrastructure and hosting major sports events. Government officials and Rio 2016 emphasized that hosting the 2016 Games would accelerate the transformation of the city and that the Games would benefit from major infrastructure investments already planned for the long-term development of Rio and the staging of the 2014 FIFA World Cup. Moreover, in order to meet the promise of affordable tickets and to relieve the pressure on the marketing program, public authorities have decided to contribute USD 692 million to the OCOG budget $(25 \%)$ in the form of subsidies. These subsidies, which would generate a positive cash flow, could vary to balance the budget between the expected revenues and expenditures. The federal state and city governments have guaranteed the financing and delivery of the infrastructures (the Village would be available to the OCOG one year before the Games), under the ultimate responsibility of the Federal Government. The federal, state and city governments have guaranteed to provide all security, medical, customs and immigration services and other government-related services at no cost to the OCOG, in accordance with their jurisdictional responsibilities. In addition, the three levels of government would also provide publicly owned venues free of charge to the OCOG. A guarantee covering any potential economic shortfall of the OCOG has been provided by the three levels of government, with each one covering one third of any potential shortfall. The financing of the development is fully guaranteed by the Federal Savings Bank of Brazil (owned by the Federal Government) and is underwritten by the Federal Government. On the other hand, this situation does not occur in the Chicago case, where there is a medium-low Government and public opinion support, raising concerns for the political, economic and financial sustainability of the project. In fact, even though the location of the Olympic Village represents one of the main points of strength, the financing of the same was not guaranteed to the IOC. The overall shortfall guarantee contains an upper limit. In Chicago 2016, the City of Chicago and the USOC (United States Olympic Committee) had made a number of legal submissions to the IOC regarding the application of the Host City Contract which were not accepted by the IOC. At the time of the visit, contrary to the IOC requirements, Chicago 2016 had not provided a full guarantee of covering any potential economic shortfall of the OCOG which included refunds to the IOC for payments made in advance or other contributions made by the IOC to the OCOG which the IOC may have to reimburse to third parties in case of any contingency like a full or partial cancellation of the Olympic Games. In conclusion, there has been noticed a general willingness of the IOC to encourage developing countries to be actively involved in this type of events and the choice of Rio to host the 2016 Olympic Games has confirmed so.

The last case studied is Tokyo that successfully won the bid to host the 2020 edition of the Olympic Games. 
Tab. 6. SWOT Analysis - Tokyo 2020.

\begin{tabular}{l|l}
\hline Strengths & Weaknesses \\
\hline - Strong Government support & \\
- Rich history and culture & - Medium public support $(70 \%$ Tokyo, $67 \%$ rest of the country) \\
- Strong economy and financial system & - High accommodation rates \\
- Sport experience & \\
$\begin{array}{l}\text { - Excellent transportation system } \\
\text { Opportunities }\end{array}$ & Threats \\
$\begin{array}{l}\text { - Well thought legacy plans (physical, social and environmental initiatives) } \\
\text { - Modernization and development of the centrally located Tokyo Bay Zone }\end{array}$ & - Japan is situated in an earthquake zone \\
- Post-Olympic use of the Olympic Village & - Uncertainty regarding the transport infrastructure budget and timelines \\
\hline
\end{tabular}

Source: Our elaboration

The project enjoys strong support from all levels of government (national, regional and local) as evidenced by commitments from the Prime Minister, the Governor of Tokyo, the Mayors of the co-host football cities, as well as resolutions passed by all the Tokyo key public authorities and also by all major political parties. As a key element of "The Sports Basic Act", the national government supports the organization of the Olympic Games in Tokyo. The TMG (Tokyo Municipal Government) would play a leading role in financing and delivering the Games alongside the NOC. The National Government is represented in the governing body and would provide all services under its remit. The National Government, through the Japan Sports Council, would finance the construction of the new Olympic Stadium (USD 1,477 million) and provide all security, medical, customs, immigration and other government-related services under its jurisdiction at no charge to the OCOG. The TMG on the other hand (which had a budget of USD 134 billion in 2012), would finance the construction of the majority of competition venues (USD 1,584 million), the IBC/MPC (International Broadcast Centre/ Main Press Center) (USD 164 million) and would underwrite the construction of the Olympic Village. In this respect the TMG has already set aside a Hosting Reserve Fund of USD 4.5 billion. The TMG would provide all security, medical and other government related services under its jurisdiction at no cost to the OCOG. Road and rail infrastructure developments would be covered by the various levels of government, according to their jurisdiction. At this point, it is important to underline that Japan has the third largest economy in the world which grew by approximately $2 \%$ in 2012. For the period 2013-2016, the Economist Intelligence Unit projects an average annual growth rate in the range of $1 \%$ to $2 \%$ (as of April 2013). The IMF (International Monetary Fund) shows a nominal GDP (Gross Domestic Product) of USD 5,964 billion (2012) and a nominal GDP per capita of USD 47,000 (2012). The Commission is confident that the Japanese economy would be able to support the necessary infrastructure development needed for the delivery of the Games. The support and engagement of the business community is evident and was very much underlined by the participation of many business leaders in the briefings. Although regional infrastructure investment will continue in the upcoming years, no capital investment is required for airports, accommodation, electrical infrastructure or security in order to host the Games. For what concerns the transportation, Tokyo's transport system has very high accessibility standards, with $90 \%$ of railway stations and $80 \%$ of buses currently accessible. This is to be further developed with the target of achieving full accessibility by Games time. A good range of dedicated lanes would operate also during the Paralympic Games. All accredited persons would benefit from free public transport, as will ticket holders on the day of the event. Wheelchairaccessible vehicles would also be provided and the majority of client groups would enjoy short travel times. This concept lends itself to the possibility for Tokyo to create a city-Centre Olympic celebration.

Furthermore, Tokyo had a well-structured legacy plan in terms of physical, social, environmental and urban development initiatives. More specifically, Tokyo's legacy strategy involves developing part of the Olympic Village into an International Exchange Plaza as a hub for international exchange research, events and cooperative projects. Using and renovating existing venues will reinvigorate the legacy of the 1964 Olympic Games and the 11 new permanent venues, some of which would also be used after the Games as national training Centre's, would create a long term foundation for the respective sports in Japan. Many of the physical legacies concern the development of the Tokyo Bay area, which would include new venues for sport, leisure and entertainment. The redevelopment of the Tokyo Bay is based on the goal of creating a society where everyone can enjoy sport and live a healthier life.

All new construction would be in accordance with the "Green Building Program" of the Tokyo 2020 vision in which the TMG places strong emphasis on energy efficient design, clean energy production and other resource efficiencies. Sustainable sourcing policies for the procurement of suppliers of goods and services would largely build on the TMG's green purchase guide and would incorporate wider social and ethical procurement issues. Tokyo 2020 aims to achieve zero waste to landfill through a comprehensive waste avoidance and minimization plan, supported by a hierarchy of reuse, recycle and recover. This covers both the construction phase and Games operations.

In conclusion, even though there were detected some threats and weakness such as the medium public support, the high accommodation rates, the fact that Tokyo is situated in 
an earthquake zone and issues regarding the respect of the timelines, the overall plan is structured in such way as to provide the preconditions to overcome them.

\section{Results and Discussion}

The analysis carried out showed both evidence of general character and a series of success factors that can significantly affect the outcome of the procedure of bid in a positive way. These may thus represent a basic framework able to provide useful guidance for the implementation of an effective management approach for the candidacy and for an optimum explanation of related financial resources.

The main evidences that emerged are as follows:

- A strong government support is almost common to all bids examined even though, that does not appear as a key success factor but a "conditio sine qua non". It is unthinkable to have even a slightest chance of hosting a mega event like the Olympics without government support. This condition is in fact present in all analyzed cases, with the exception of Chicago 2016 where the average level of support represented one of the main causes of failure of the candidature.

- The public opinion, generally medium-low, it does not appear to be a critical issue that could affect negatively the outcome of the bid process, in fact both the 2012 London and 2016 Rio candidacies did not have a high public opinion support, but yet they both won the bid.

- It cannot be expressed any consideration on the role as a key success factor the experience in presenting bids: in fact the 3 bids of Istanbul $(2000,2008,2020)$ and those of Madrid (2012, 2016, 2020) were all unsuccessful while the second bid attempt of Tokyo and Beijing were successful (2020 and 2008).

As for the main key success factors emerged from our analysis are:

- The overall logistics of the event. In this factor are considered both the presence of a suitable accommodation system for the flows of visitors expected for the event, and the importance of the location of the Olympic village, like in the 2012 London candidacy, but most importantly the efficiency of the transport system that if omitted, threatens to become a major obstacle, as happened for the 2008 Istanbul candidacy.

- Consistency with policies of urban, social and economic development. On the one hand, like in the two Asian cases, the consistency among the development policies constitutes a guarantee for the performant execution of the event and the sustainability of the related urban, social and economic-financial effects; on the other hand, like in the Brazilian case, the Olympic Games themselves were able to amplify the benefits arising from the current development policies. In contrast, the lack of this aspect affects in a substantial way the positive outcome of the bid.

- Bid team composition which includes all the primary and secondary stakeholders. This factor, although not directly mentioned emerges from the organizational and management skills that such event requires. Including in the bid team highly skilled professionals with expertise in the organization and management of mega sport events, allows to create a stronger and more structured candidacy.

In coherence with the results, we can see below a preliminary SWOT Analysis, discussing the potentialities of the Rome 2024 candidacy, in race with Paris, Budapest and Los Angeles and the hypothetical managerial choices and investment which may increase the chances of success in the biding process.It is appropriate to specify that, given the hypothetical nature and the preliminary analysis conducted, entries accompanied by a question mark represent uncertainties that only time can confirm or not.

Tab. 7. SWOT Analysis - Rome 2024.

\begin{tabular}{ll}
\hline Strengths & Weaknesses \\
\hline - Strong Government support & - Public opinion support? \\
- Location of the Olympic Park (existing venues) & - Consistency with policies of urban and social development? \\
- Rich history and Culture & $-\ldots$ \\
- ..... & Threats \\
Opportunities & - Difficulty in ensuring that all facilities can be completed on time? \\
- Continental rotation & - Uncertainty to cover potential economic shortfall of OCOG? \\
- ..... & - The potential bid of Paris to host the centennial Olympics (1924-2024) \\
\hline
\end{tabular}

Source: Our elaboration

So far, the points of strength on which the candidacy of the Italian capital can count are the lure of its history and culture, the location of the Olympic Park that would allow the athletes to quickly reach the competition venues, and last the strong public support, that as demonstrated by the above considerations even if necessary it is not sufficient to affect the outcome of the bid evaluation. In addition, the candidacy may benefit from a continental rotation that would see the possibility of the Olympics being held in Europe very likely; but this will benefit the Italian city only against Los Angeles, as Paris and Budapest are also European realities.

According to the analysis carried out so far in the present work, it is evident that the situation described above alone is not able to ensure a good chance of success of the Rome 
2024 bid. In fact, it is vital to limit the effect of certain weaknesses and threats not yet established, or even better to transform them into strengths through a managerial approach able to invest the available resources where required.

More specifically, the development policies should aim to fill the current venues and infrastructure gap. Even though the majority of the venues already exist, their current state make them almost inappropriate to use and therefore need restructure, some examples are the Flaminio stadium, Pratoni del Vivaro, Villa Ada and other smaller venues. Furthermore, the public transportation network requires similar reasoning as it would necessitate a further efficiency. Both the athletes' village and the media center should be built, as opposed to Los Angeles that already has such infrastructures (Official Report Olympic of Rome 2024). In this regard, it would be appropriate to invest a good part of the estimated US\$ 35 billion budget to support such shortcomings and criticalities, guaranteeing at the same time the coverage of these investments, not only through the contribution of the IOC, but also through sponsorships and private partnerships as happened for the analyzed success cases. If this were to happen, the threat generated by the IOC willingness to exploit a hypothetical Olympics centennial (1924-2024) of the Paris candidacy, would certainly a specific weight of modest extent.

\section{Conclusions}

From the cases examined it is possible to draw some general conclusions and some specific outlines relative to the candidature of Rome for the 2024 Olympics. As for the general conclusions, confirm as widely claimed in literature, the strong interest in hosting a mega event like the Olympic Games in order to benefit in economic and social level. This interest is not always reflected the required amenities of the candidate. Such amenities are not to be distinguished only by aspects tied exclusively to the territory (Geomorphological, climatic and, more in general, the geographical characteristics). In fact, the amenities include the tangible and intangible assets of the location. As for the tangible assets, we firstly point out the sporting facilities, the connection, transport and tourism infrastructure. Among the intangible assets, are found the policies to be adopted to attract sporting events, the location in terms of sports marketing, the experience and expertise in organizing events and the economic potential. The set of intangible assets is completed by the residents, who, with their characteristics in terms of needs, moods and expressed desires, come together to define the event's receptivity in its qualitative aspects. In this view, the analysis has led to highlight some crucial factors in order to be really competitive in a procedure of the Olympic bid among which a high government support, adequate infrastructures connected to an efficient logistics system and certainly a consistency of development policies on economic, social and urban level. The careful consideration of the amenities therefore contributes, already in the phase of the development of the event's concept and the idea, to lay the foundations for the success of the event itself as well as to provide the best chance of success of the candidature. In this regard, relatively to the specific conclusions, Rome's candidacy to host the 2024 Olympic Games, albeit with a good potential guaranteed by a strong government support and the undeniable historic and cultural charm of the Italian Capital has several infrastructure and logistic criticalities. Hence, it is possible to conclude with the evident need to address a series of investments designed to improve these issues, while maintaining the financial and economic sustainability, indispensable in any application. A direction of further research could be the assessment of the same nomination of the city of Rome after the closure to the procedure of bid (in 2017) to verify if what speculated found practical basis in reality.

\section{References}

[1] Alberts, H. C. (2009). Berlin's failed bid to host the 2000 Summer Olympic Games: urban development and the improvement of sports facilities. International journal of urban and regional research, 33 (2), 502-516.

[2] Bandyopadhyay, K. (2014). In search of an Olympic legacy: the story of India's failed Olympic bid. Sport in Society, 17 (5), 609-616.

[3] Baxter, P., \& Jack, S. (2008). Qualitative case study methodology: Study design and implementation for novice researchers. The qualitative report, 13 (4), 544-559.

[4] Booth, D., \& Tatz, C. (1994). Swimming with the big boys? The politics of Sydney's 2000 Olympic bid'. Sporting traditions, 11 (1), 3-23.

[5] Brown, R., Cox, G., \& Owens, M. (2012). Bid, delivery, legacy-Creating the governance architecture of the London 2012 Olympic and Paralympic Games legacy. Australian Planner, 49 (3), 226-238.

[6] Eisenhardt, K. M. (1989). Building theories from case study research. Academy of management review, 14 (4), 532-550.

[7] Glynn, M. A. (2008). Configuring the field of play: How hosting the Olympic Games impacts civic community. Journal of Management Studies, 45 (6), 1117-1146.

[8] Gratton, C., \& Preuss, H. (2008). Maximizing Olympic impacts by building up legacies. The International Journal of the History of Sport, 25 (14), 1922-1938.

[9] Haugen, H. Ø. (2005). Time and space in Beijing's Olympic bid. Norsk Geografisk Tidsskrift-Norwegian Journal of Geography, 59 (3), 217-227.

[10] Hautbois, C., Parent, M. M., \& Séguin, B. (2012). How to win a bid for major sporting events? A stakeholder analysis of the 2018 Olympic Winter Games French bid. Sport Management Review, 15 (3), 263-275.

[11] Hiller, H. H. (2000). Mega - events, urban boosterism and growth strategies: an analysis of the objectives and legitimations of the Cape Town 2004 Olympic Bid. International journal of urban and regional research, 24 (2), 449-458. 
[12] Hitch, L. C., \& Mihalik, B. J. (2002). The Salt Lake city olympic bid process. Journal of Sport \& Tourism 7 (3): 37-38.

[13] IOC (2001). Report of the IOC Evaluation Commission for the Games of the XXIX Olympiad in 2008. International Olympic Committee, Lausanne, Switzerland.

[14] IOC (2005). Report of the IOC Evaluation Commission for the Games of the XXX Olympiad in 2012. International Olympic Committee, Lausanne, Switzerland.

[15] IOC (2009). Report of the IOC Evaluation Commission for the Games of the XXXI Olympiad in 2016. International Olympic Committee, Lausanne, Switzerland.

[16] IOC (2013). Report of the IOC Evaluation Commission for the Games of the XXXII Olympiad in 2020. International Olympic Committee, Lausanne, Switzerland.

[17] Kasimati, E. (2003). Economic aspects and the Summer Olympics: a review of related research. International journal of tourism research, 5 (6), 433-444.

[18] Lee, C. K., \& Taylor, T. (2005). Critical reflections on the economic impact assessment of a mega-event: the case of 2002 FIFA World Cup. Tourism management, 26 (4), 595-603.

[19] Liao, H., \& Pitts, A. (2006). A brief historical review of Olympic urbanization. The International Journal of the History of Sport, 23 (7), 1232-1252.

[20] Little, C. (1997). From One Brickpit to Another: The Ancient History of the Sydney Olympic Bid. SPORTING TRADITIONS, 14, 79-90.

[21] Newman, P. (2007). "Back the Bid": the 2012 Summer Olympics and the governance of London. Journal of urban affairs, 29 (3), 255-267.

[22] O'Brien, D. (2006). Event business leveraging the Sydney 2000 Olympic Games. Annals of Tourism Research, 33 (1), 240-261.

[23] O'Brien, D. and Chalip, L. (2007), "Executive training exercise in sport event leverage", International Journal of Culture, Tourism and Hospitality Research, Vol. 1 No. 4, pp. 296-304.
[24] Rose, A. K., \& Spiegel, M. M. (2011). The olympic effect*. The Economic Journal, 121 (553), 652-677.

[25] Shank, D. M. (2009), Sports Marketing: A Strategic Perspective, $4^{\text {th }}$ ed., Prentice-Hall, Upper Saddle River, NJ.

[26] Shoval, N. (2002). A new phase in the competition for the Olympic gold: the London and New York bids for the 2012 Games. Journal of urban affairs, 24 (5), 583-599.

[27] Swart, K., \& Bob, U. (2004). The seductive discourse of development: the Cape Town 2004 Olympic bid. Third World Quarterly, 25 (7), 1311-1324.

[28] Tufts, S. (2004). Building the 'competitive city': Labour and Toronto's bid to host the Olympic Games. Geoforum, 35 (1), 47-58.

[29] van Dijk, T., \& Weitkamp, G. (2014). Power in Dreams? The Spatial Effects of Chicago's Failed Olympic Bid. International Planning Studies, 19 (2), 111-131.

[30] Waitt, G. (2003). Social impacts of the Sydney Olympics. Annals of Tourism Research, 30 (1), 194-215.

[31] Westerbeek, H. M., Turner, P., \& Ingerson, L. (2002). Key success factors in bidding for hallmark sporting events. International Marketing Review, 19 (3), 303-322.

[32] White, L. (2011). The Sydney 2000 Olympic Games bid: Marketing indigenous Australia for the millennium games. International Journal of the History of Sport, 28 (10), 14471462.

[33] Xing, X., Church, A. G., O'Reilly, N., Pegoraro, A., Nadeau, J., Heslop, L., \& Séguin, B. (2008). Olympic Games host and bid city marketing: exploring issue management in the relationships among event stakeholder groups. International Journal of Sports Marketing and Sponsorship, 9 (4), 77-91.

[34] Zhao, X. (2002). From Indifference to Cooptation: A Study of the Relationship between the Government and NGOs in China's Green Olympic Bid Campaign. The Nonprofit Review, 2 (2), 73-82. 